\title{
The Expression of Riboflavin Transporters in Human Colorectal Cancer
}

\author{
VALERIA TUTINO ${ }^{1}$, MARIANNA LOREDANA DEFRANCESCO ${ }^{2}$, MARIA TOLOMEO ${ }^{2}$, \\ VALENTINA DE NUNZIO ${ }^{1}$, DIONIGI LORUSSO ${ }^{1}$, DIDIER PALENI ${ }^{3}$, \\ MARIA GABRIELLA CARUSO ${ }^{1}$, MARIA NOTARNICOLA ${ }^{1}$ and MARIA BARILE ${ }^{2}$ \\ ${ }^{I}$ National Institute of Gastroenterology, S. de Bellis Research Hospital, Castellana Grotte, Bari, Italy; \\ ${ }^{2}$ Department of Bioscience, Biotechnology and Biopharmaceutics, A. Moro University of Bari, Bari, Italy; \\ ${ }^{3}$ Bio Even, Mathay, France
}

\begin{abstract}
Background/Aim: Riboflavin transport in enterocytes is mediated by three translocators: RFVT3 located on the apical membrane, and RFVT1 and RFVT2 on the basolateral membrane. The aim of this study was to investigate whether the expression levels of RFVTs are altered in human colorectal cancer (CRC). Materials and Methods: In human colon adenocarcinoma cell lines (CaCo2, DLD-1, HT-29) and in tissues of patients with CRC, gene and protein expression levels were evaluated by real time-polymerase chain reaction and western blotting. Intracellular flavin content was determined by highperformance liquid chromatography. Results: RFVT3 and RFVT2 gene and protein expression levels were higher in DLD-1 and HT-29 compared to Caco2 cells. In HT-29 cells, the RFVT1 protein level was drastically lower. These differences are presumably responsible for the higher total flavin content in DLD-1 and HT-29 cells. In tumor tissues of patients with CRC, RFVT1 content was reduced at both protein and mRNA levels compared to normal mucosa. RFVT3 and RFVT2 gene expression levels were increased, while protein expression was reduced, with a small reduction in riboflavin amount. Conclusion: This study provides first evidence that transcription/translation of RFVTs are profoundly altered in CRC.
\end{abstract}

Riboflavin, otherwise known as vitamin B2, is an essential dietary component and represents the precursor of flavin mononucleotide (FMN) and flavin adenine dinucleotide (FAD), that are important enzymatic cofactors required for

Correspondence to: Maria Barile, Department of Bioscience, Biotechnology and Biopharmaceutics, University of Bari A. Moro, via Orabona, 4, I-70125 Bari, Italy. E-mail: maria.barile@uniba.it

Key Words: Colorectal cancer, riboflavin transporters, riboflavin, cell lines, flavin cofactor homeostasis. carbohydrate, amino acid and lipid metabolism, and other cellular regulatory roles (1-5). Humans, being unable to synthesize riboflavin, must obtain it from food, in particular from milk, meats, fatty fish and green vegetables, and, to a lesser amount, from intestinal microflora; after intestinal absorption, mainly occurring in the small intestine, riboflavin is distributed from the blood to several tissues $(1,2,6)$.

In different cells, riboflavin uptake occurs via specialized carrier-mediated processes supported by three specific members of the solute carrier family 52 (SLC52A), identified and named riboflavin transporter 1 (RFVT1; SLC52A1), RFVT2 (SLC52A2), and RFVT3 (SLC52A3), respectively (6-9). Alterations of these proteins were recently correlated with rare inherited neuromuscular diseases (10). Inside the cells, riboflavin is phosphorylated to FMN by riboflavin kinase (E.C. 2.7.1.26) and it is subsequently metabolized to FAD by FAD synthase (E.C. 2.7.7.2) $(11,12)$, which also participates in cofactor delivery to the appropriate apo-flavoenzymes during holoenzyme biogenesis (13).

At the apical membrane of enterocytes, riboflavin is absorbed by the action of RFVT3, which is expressed at a higher level compared with the other riboflavin transporters. The vitamin is then released into blood by RFVT2 and RFVT1, which are mainly localized at the basolateral membrane domain $(2,8,14,15)$.

Studies have shown that a low intake of dietary riboflavin can lead to negative health consequences, that include the development of several cancer such as colorectal cancer (CRC) $(16,17)$. Riboflavin nutritional status and riboflavin availability in intestinal cells have been shown to be relevant to normal cellular functions, including proliferation, growth and survival (18). Interestingly, plasma and tissue riboflavin levels were found decreased in patients with cervical intraepithelial neoplasia and cervical squamous cell carcinoma as compared with normal controls. In the tumor tissues of these patients, high RFVT3 expression levels were found and these levels were positively correlated with the 
tumor stage, suggesting a protective role of RFVT3 against riboflavin deficiency associated with cervical carcinogenesis (19). Different results were obtained in gastric cancer, where a decrease in RFVT3 mRNA and protein expression were reported (20). To date, in human CRCs, the profile of expression of RFVTs has been under investigated and it is still not known whether there are other factors, such as tumor stage and tumor grade differentiation, which can influence flavin absorption and transport.

Therefore, the aim of the present study was to evaluate gene expression and protein levels of RFVTs in three human colon adenocarcinoma cell lines with different degrees of differentiation: $\mathrm{CaCo} 2$ cell line (well-differentiated); DLD1 cell line (well-differentiated with Dukes' $\mathrm{C}$ characteristics) and HT-29 cell line (moderately differentiated). Moreover, the gene and protein expression levels of RFVTs were also measured in tumor and in surrounding normal mucosa of patients with CRC. To gain further insight into intestinal homeostasis of flavins in cancer, the basal levels of riboflavin, FAD and FMN were also assessed both in three cell lines and in intestinal tissues of patients with CRC.

\section{Materials and Methods}

Cell culture conditions. The human colon adenocarcinoma cell lines CaCo2, DLD-1 and HT-29 were obtained from the Interlab Cell Line Collection (Genoa, Italy). The cells were seeded at a density of $2 \times 10^{5}$ cells $/ 10 \mathrm{ml}$ of RPMI 1640 medium for $\mathrm{CaCo} 2$ and DLD1 cells, and McCoy's 5A medium for HT-29 cells in $100 \mathrm{~mm}$ tissue culture dishes (Corning Costar Co., Milan, Italy), supplemented with $10 \%$ fetal bovine serum, $1 \%$ non essential amino acids, $2 \mathrm{mM}$ glutamine, $100 \mathrm{U} / \mathrm{ml}$ penicillin, $100 \mu \mathrm{g} / \mathrm{ml}$ streptomycin, in monolayer cultures, and incubated at $37^{\circ} \mathrm{C}$ in a humidified atmosphere containing $5 \% \mathrm{CO}_{2}$ in air. At confluence, the grown cells were harvested and serially subcultured with a 1:4 split ratio. All cell culture components were purchased from Sigma Aldrich (Milan, Italy).

Patients. Twenty-four consecutive patients (nine men and 15 women, mean age $=68.58 \pm 11.37$ years) undergoing surgery for CRC were enrolled in the study. They all gave informed consent to take part in the study. Colorectal normal mucosa and cancer tissue were obtained from each according to a standardized procedure. Samples of mucosa were taken from macroscopically normal areas of intestine at $10 \mathrm{~cm}$ from the neoplastic lesion. Specimens were taken within $1 \mathrm{~h}$ after the surgical procedure and stored at $-80^{\circ} \mathrm{C}$ until assayed. The laboratory analyses were performed blindly with respect to the clinical characteristics and histopathologic al features of the samples. Clinical and histopathological features of each patient were recorded and are reported in Table I.

RFVT gene expression analysis. Human RFVT mRNA levels were analyzed by real time-polymerase chain reaction (RT-PCR) assay. Total tissue RNA, isolated with TRI-Reagent (Mol. Res. Centre Inc., Cincinnati, OH, USA), was reverse transcribed in $20 \mu \mathrm{l}$ final volume at $41^{\circ} \mathrm{C}$ for $60 \mathrm{~min}$ using $30 \mathrm{pmol}$ antisense primer for human RFVT1, RFVT2, RFVT3 and $\beta$-actin gene (Table II). Real-
Table I. Clinical and histopathological features of patients with colorectal cancer.

\begin{tabular}{lc}
\hline Factor & Cases $(\mathrm{n}=24)$ \\
\hline Age, years & \\
$\quad$ Mean \pm SD & $68.58 \pm 11.37$ \\
Gender & \\
$\quad$ Male & 9 \\
Female & 15 \\
Tumor side ${ }^{1}$ & \\
Right & 7 \\
Left & 17 \\
Tumor stage ${ }^{2}$ & \\
I & 2 \\
II & 5 \\
III & 10 \\
IV & 7 \\
Histological grading & \\
Well differentiated & 7 \\
Moderately differentiated & 11 \\
Poorly differentiated & 6 \\
\hline
\end{tabular}

${ }^{1}$ Right side: hepatic flexure, cecum and ascending colon; left side: descending colon, sigmoid and rectum; ${ }^{2}$ clinical staging performed using the Union for International Cancer Control system.

time PCRs were performed in $25 \mu$ f final volume containing $2 \mu \mathrm{l}$ of cDNA, master mix with SYBR Green (iQ SYBR Green Supermix Bio-Rad Laboratories, Milan, Italy) and sense and antisense primers for each target gene and the $\beta$-actin gene (Table II). Real-time PCR was carried out as previously described (21). All expression data were normalized using $\beta$-actin as an internal control. Gel electrophoresis was used to confirm the specificity of PCR products.

Protein extraction and western blotting analysis. Total proteins from cell lines and tissue samples were extracted using RIPA buffer (Sigma-Aldrich). After quantization of protein concentration by a standard Bradford assay (Bio-Rad Laboratories), equal amounts of protein $(50 \mu \mathrm{g})$ were separated by sodium dodecyl sulphatepolyacrylamide gel electrophoresis and subsequently transferred onto a polyvinylidene difluoride membrane (Bio-Rad Laboratories). The primary antibodies were directed against the following proteins: SLC52A1-RFVT1, SLC52A2-RFVT2 (Thermo Fisher Scientific, Rockford, IL, USA), SLC52A3 (MyBioSource, San Diego, CA, USA), $\beta$-actin (Cell Signaling, Beverly, MA, USA) and $\alpha$-tubulin (Sigma-Aldrich). After overnight incubation, a horseradish peroxidase-conjugated secondary antibody (Bio-Rad Laboratories) was used. The immunoreactive bands were visualized and analyzed using chemiluminescence detection system (ChemiDoc XRS apparatus and software; Bio Rad Laboratories) and the proteins detected were normalized against $\beta$-actin.

Determination of flavin levels. Flavin content was measured in human colon adenocarcinoma cell lines and in tissues of tumor and normal mucosa of 11 patients with CRC. Cell pellets and about $45 \mathrm{mg}$ of tissue samples were re-suspended in 150 and $300 \mu \mathrm{l}$ of lysis buffer respectively $(50 \mathrm{mmol} / 1 \mathrm{Tris}-\mathrm{HCl} \mathrm{pH} 7.5,1 \%$ Triton $\mathrm{X}$ $100,5 \mathrm{mmol} / 1 \quad \beta$-mercaptoethanol, $1 \mathrm{mmol} / \mathrm{l} \mathrm{NaF}, 0.1 \mathrm{mmol} / 1$ 
Table II. Sequences of amplification primers.

\begin{tabular}{|c|c|}
\hline Gene & Primer \\
\hline \multicolumn{2}{|l|}{ RFVT1 } \\
\hline Sense & 5'-AAAAGACCTTCCAGAGGGTTG-3' \\
\hline Antisense & 5'-AGCACCTGTACCACCTGGAT-3' \\
\hline \multicolumn{2}{|c|}{ RFVT2 } \\
\hline Sense & 5'-CCCTGGTCCAGACCCTA-3' \\
\hline Antisense & 5'-ACACCCATGGCCAGGA-3' \\
\hline \multicolumn{2}{|c|}{ RFVT3 } \\
\hline Sense & 5'-CCTTTCCGAAGTGCCCATC-3' \\
\hline Antisense & 5'-AGAAGGTGGTGAGGTAGTAGG-3' \\
\hline \multicolumn{2}{|c|}{$\beta$-Actin } \\
\hline Sense & 5'-AAAGACCTGTACGCCAACACAGTGCTGTCTGG-3' \\
\hline Antisense & 5'-CGTCATACTCCTGCTTGCTGATCCACATCTGC-3' \\
\hline
\end{tabular}

phenylmethylsulfonyl fluoride) and protease-inhibitor cocktail (Roche Diagnostics GmbH, Mannheim, Germany; 1 tablet/10 ml of lysis buffer). After homogenization and centrifugation at $13000 \times g$ for $10 \mathrm{~min}$ at $4^{\circ} \mathrm{C}$, the supernatant was recovered as cell lysate and protein concentration was measured by a standard Bradford assay. Riboflavin, FMN, and FAD in neutralized perchloric acid extracts of cell lysates $(0.45 \mathrm{mg}$ protein) were measured by highperformance liquid chromatography (HPLC), essentially as previously described (22). Quantitative determinations of flavins were carried out with a calibration curve made in each analysis with standard solutions diluted in the extraction solution.

Statistical analysis. The significance of the differences between the three groups of experimental cells were evaluated with one-way analysis of variance (ANOVA) and Tukey's multiple comparison test. The differences in RFVT1, RFVT2 and RFVT3 mRNA levels, as well as the differences in flavin content, between normal colon mucosa and cancer were analyzed by paired $t$-test. The MannWhitney test was used to analyze the differences in RFVT mRNA and protein levels in relation to clinical parameters such as age, sex, tumor site, stage of disease and histological differentiation. Differences were considered statistically significant with a $p$-value of less than 0.05 .

\section{Results}

Figure 1 shows mRNA levels of RFVTs in three human colon adenocarcinoma cell lines with a different degree of differentiation, namely $\mathrm{CaCo} 2$, DLD-1 and HT-29. In particular, no significant difference was detected in RFVT1 mRNA levels among the three cell lines (Figure 1A), whilst the levels of $R F V T 2$ and $R F V T 3$ gene expression were significantly higher in HT-29 cells than CaCo2 and DLD-1 cells $(p<0.001$ and $p<0.0001$, ANOVA and Tukey's multiple comparison test, respectively; Figure $1 \mathrm{~B}$ and $\mathrm{C}$ ). As regards the protein expression levels of RFVTs in cell lines, a lack of expression of RFVT1 was found in HT-29 cells ( $p<0.001$ and $p<0.0001$, ANOVA and Tukey's multiple comparison test; Figure 2A). In

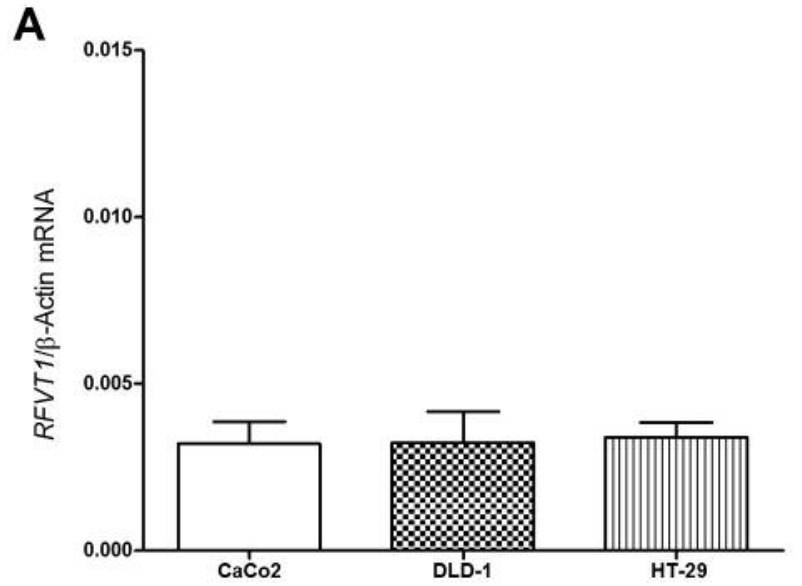

B
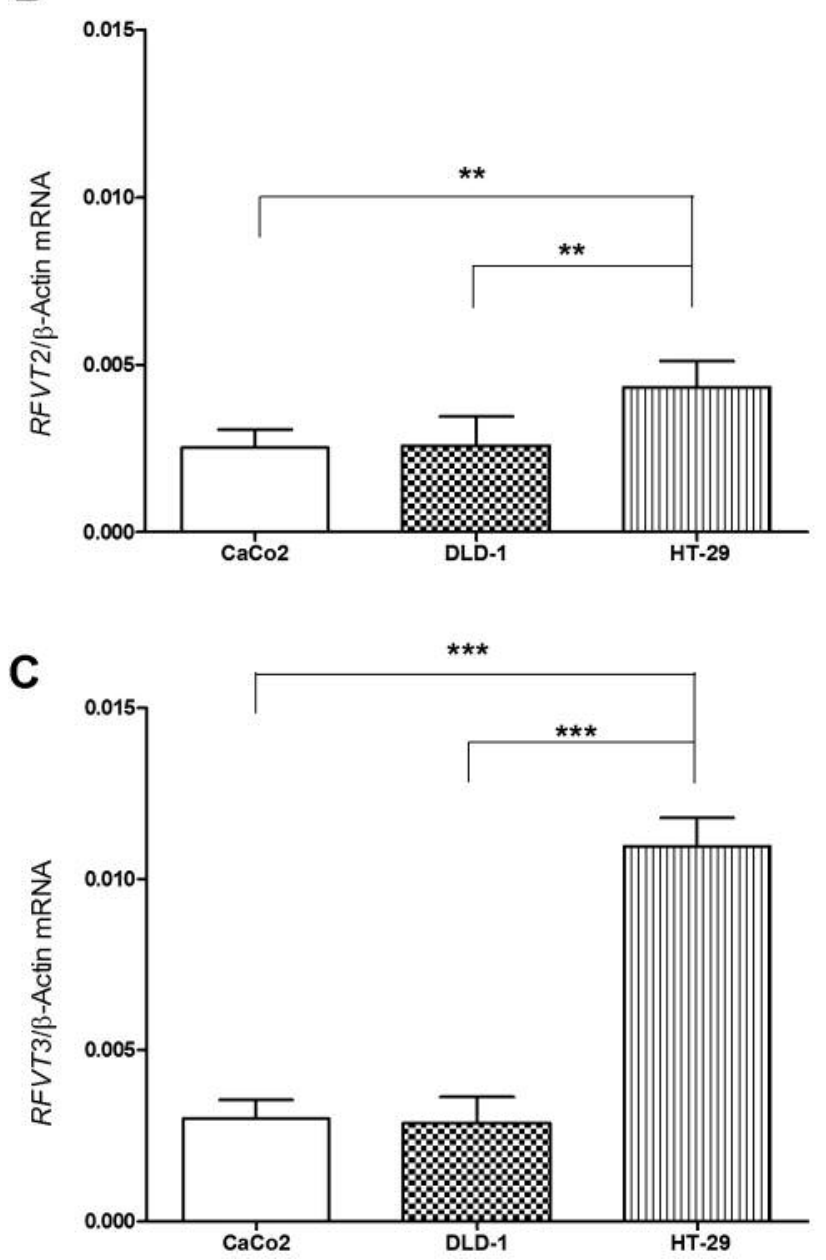

Figure 1. Riboflavin transporter (RFVT) mRNA levels in CaCo2, DLD1 and HT-29 cells. A: RFVT1, B: RFVT2, and C: RFVT3 mRNA levels in three human colon adenocarcinoma cell lines with different degrees of differentiation: CaCo2, DLD-1 and HT-29. Data are expressed relative to that for $\beta$-actin $m R N A$. Significantly different at: $* * p<0.001$ and $* * * p<0.0001$, ANOVA and Tukey's multiple comparison test. All data represent the results of three different experiments (mean $\pm S D)$. 

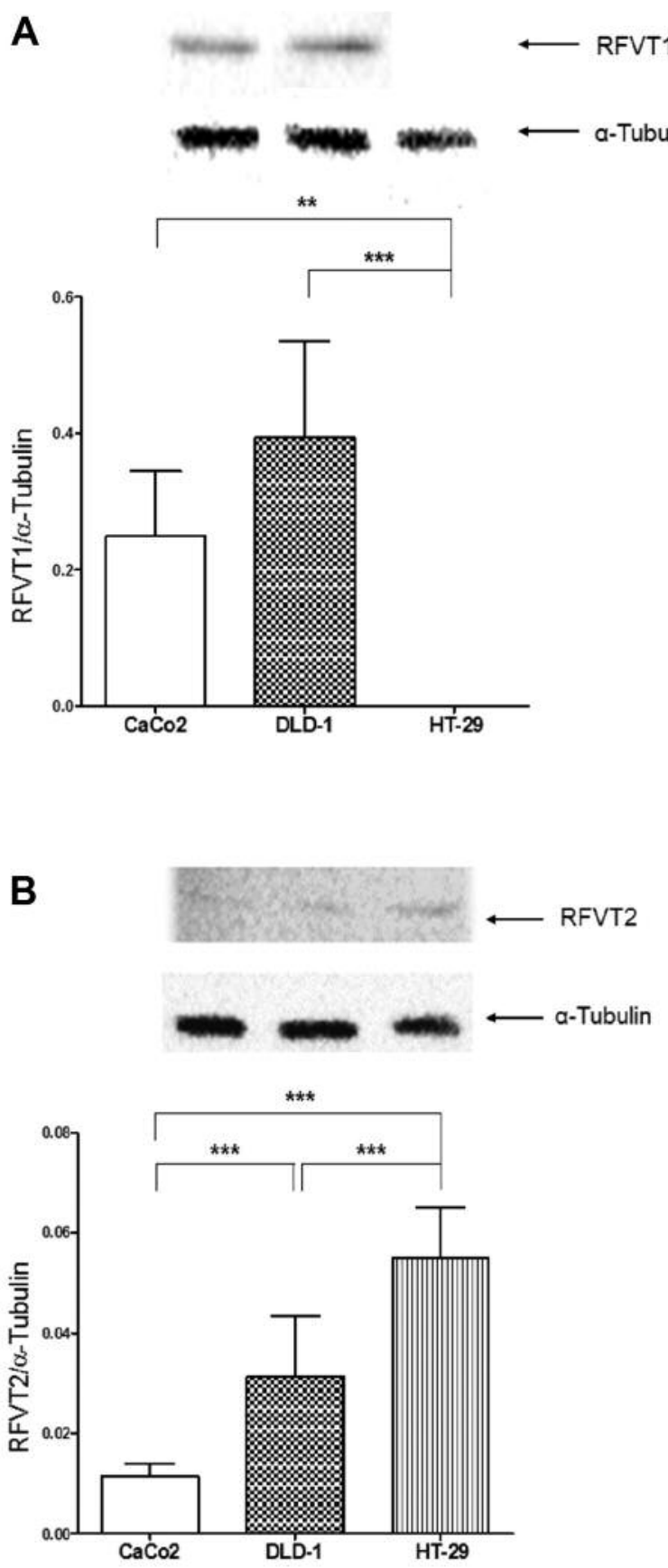

concordance with gene expression, protein levels of RFVT2 and RFVT3 were also significantly higher in HT-29 with respect to $\mathrm{CaCo} 2$ and to DLD- 1 cells $(p<0.001$ and $p<0.0001$, ANOVA and Tukey's multiple comparison test; Figure 2B and C). In addition, RFVT2 protein levels was significantly higher in DLD- 1 compared to $\mathrm{CaCo} 2$ cells $(p<0.0001$, ANOVA and Tukey's multiple comparison test; Figure 2B).

In order to confirm that alteration in the expression of flavin transporters was associated with CRC, gene and
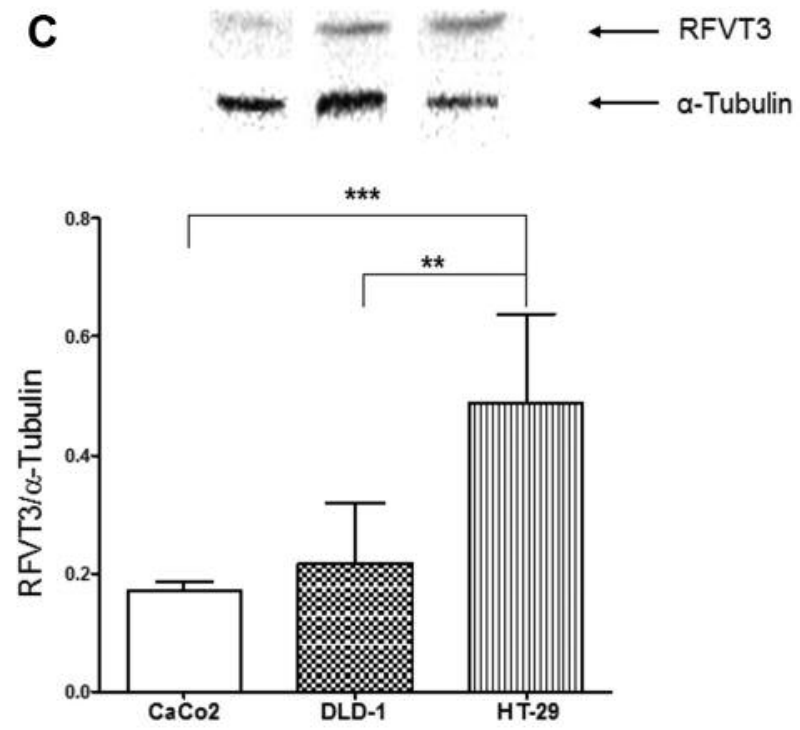

Figure 2. Western blotting analysis of the expression of riboflavin transporter (RFVT) proteins in CaCo2, DLD-1 and HT-29 cells. A: RFVT1, B: RFVT2 and C: RFVT3 expression normalized with that for $\alpha$-tubulin. Significantly different at: $* * p<0.001$, and $* * * p<0.0001$, ANOVA and Tukey's multiple comparison test. All data represent the results of three different experiments (mean $\pm S D$ ).

protein expression levels were evaluated for RFVTs in tumor tissue and in surrounding normal mucosa from 24 patients with CRC, whose clinical and histopathological features are described in Table I. Figure 3 shows RFVTI gene expression level to be significantly lower in cancer tissue compared to normal mucosa; on the contrary, levels of RFVT2 and RFVT3 gene expression were significantly higher in tumor tissue $(p<0.0001$, ANOVA and Tukey's multiple comparison test), in accordance with changes observed in cell models. Nevertheless, in the tissues, RFVT1 and RFVT2 protein expression was significantly lower in tumor as compared to normal mucosa $(p<0.001$ and $p<0.0001$, ANOVA and Tukey's multiple comparison test, respectively; Figure 4A and B); while a small reduction in RFVT3 protein levels was found, although it was not statistically significant (Figure 4C). No association was found between both mRNA and protein levels of RFVTs and age, sex, tumor site, disease stage and histological differentiation (data not shown).

To understand whether changes in the expression levels of RFVTs may alter the flavin content or its distribution in enterocytes, the basal levels of FAD, FMN and riboflavin were measured by HPLC in extracts obtained both human colon adenocarcinoma cell lines and tissue samples. Total flavin amounts in DLD-1 and HT-29 were significantly higher compared with $\mathrm{CaCo} 2$ cells $(p<0.0001$, ANOVA and Tukey's multiple comparison test; Figure 5A). In particular FAD content, which represents the major contribution to the total 


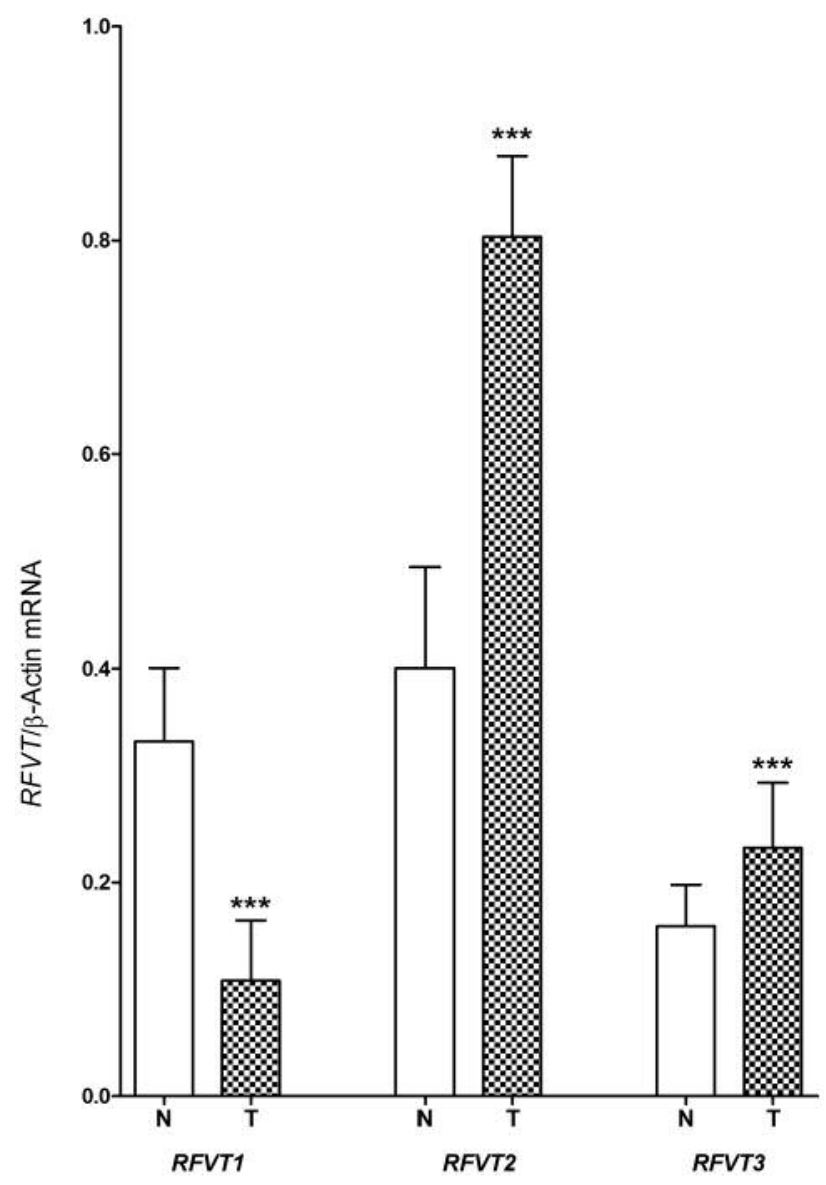

Figure 3. Riboflavin transporter (RFVT) mRNA levels in intestinal normal mucosa $(N)$ and cancer tissue $(T)$ from 24 patients with colorectal cancer. Data are expressed relative to that for $\beta$-actin mRNA. ***Significantly different at $p<0.0001$, paired $t$-test. All data represent the results of three different experiments (mean $\pm S D)$.

acid-extractable flavins in cells, was significantly enhanced in DLD-1 and HT-29 compared with $\mathrm{CaCo} 2$ cells as shown in Figure 5B $(p<0.0001$, ANOVA and Tukey's multiple comparison test). Moreover, a statistically significantly lower FMN content was found in DLD-1 compared to $\mathrm{CaCo} 2$ and HT-29 cell lines $(p<0.0001$, ANOVA and Tukey's multiple comparison test; Figure 5C), while no significant differences in riboflavin amount were found (Figure 5D).

In the tissues, from patients with CRC, the content of total flavins, as well as FMN, did not show any variation between tumor and normal mucosa (Figure 6A and C). FAD was the most representative flavin, but no statistically significant differences in its content were found between normal and tumor tissues (Figure 6B), despite the slightly lower RFVT3 content. Nevertheless, a small but statistically significant reduction in riboflavin amount was observed in cancer tissue compared to normal surrounding mucosa of patients with CRC $(p<0.001$, ANOVA and Tukey's multiple comparison test; Figure 6D).

\section{Discussion}

In the present study, we demonstrated, for the first time as far as we are aware, changes in expression levels of riboflavin transporters in human CRC.

In the cell models used, both mRNA and protein levels of RFVT3 and RFVT2 were higher in HT-29 compared to Caco2 and DLD-1 cells. This finding suggests an association between the increase in the expression level of RFVT3 and RFVT2 and the degree of tumor differentiation. Interestingly, the behavior of RFVT1 expression was different from that of the other two transporters: no significant difference in RFTVI mRNA level was observed in any of the tested cell lines. This result is in line with a previous study, conducted on NCM460 cells maintained under riboflavin deficiency, in which no changes in RFVT1, but an increase of RFVT3 and RFVT2 expression levels were found (23). In addition, we found a loss of RFVT1 protein expression in HT-29 cells. RFVT1 is expressed at the basolateral membrane of intestinal cells, therefore the disappearance of this protein in HT-29 cells may be due either to a loss in cellular polarity or to a higher rate of RFVT1 protein degradation in these cells.

Moreover, in less differentiated cells, the total flavin amount was statistically higher, probably because of an adaptive mechanism of tumor cells, which apparently become greedy for this vitamin. Thus, tumor cells appear to increase the rate of flavin intake and, at the same time, reduce the rate of its export. In fact, we hypothesize that RFVT3 is the major factor responsible for the increase of the observed intracellular flavin content. Furthermore, the increase in flavin content also occurred in DLD-1 cells, where there was no decrease in RFVT1 expression level.

The increase of flavin content in DLD-1 and HT-29 cells is essentially linked to the contribution of FAD, the main enzymatic cofactor, which is synthesized by FAD synthase, operating at a rate which overcomes that of riboflavin transport (2). The decrease in FMN content observed in DLD1 cells compared with the other cell lines might be explained by a concomitant variation in intracellular enzyme activities of riboflavin kinase/FAD synthase. Therefore, it can be hypothesized that at the transcriptional/post-transcriptional level, cancer induces conditions of intracellular stress, mimicking those occurring in the absence of the vitamin, leading to adaptation of flavin intestinal homeostasis.

In tumor tissues of patients with CRC, the adaptive response of RFVTs to tumorigenesis was confirmed. In particular, we found a reduction in both protein and gene expression levels of $R F V T 1$, thus suggesting a reduced ability to export riboflavin in the blood, while a different behavior 
A
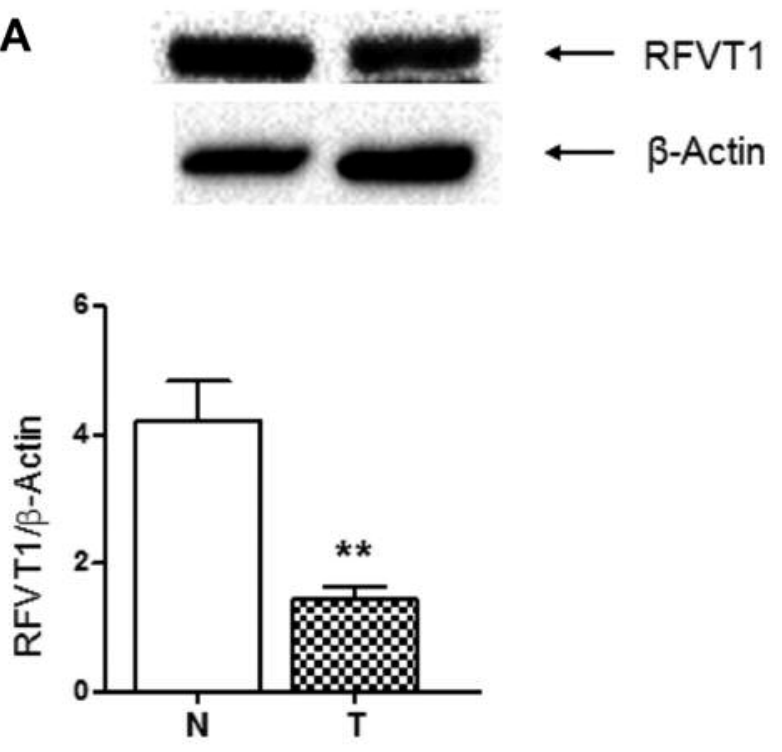

B
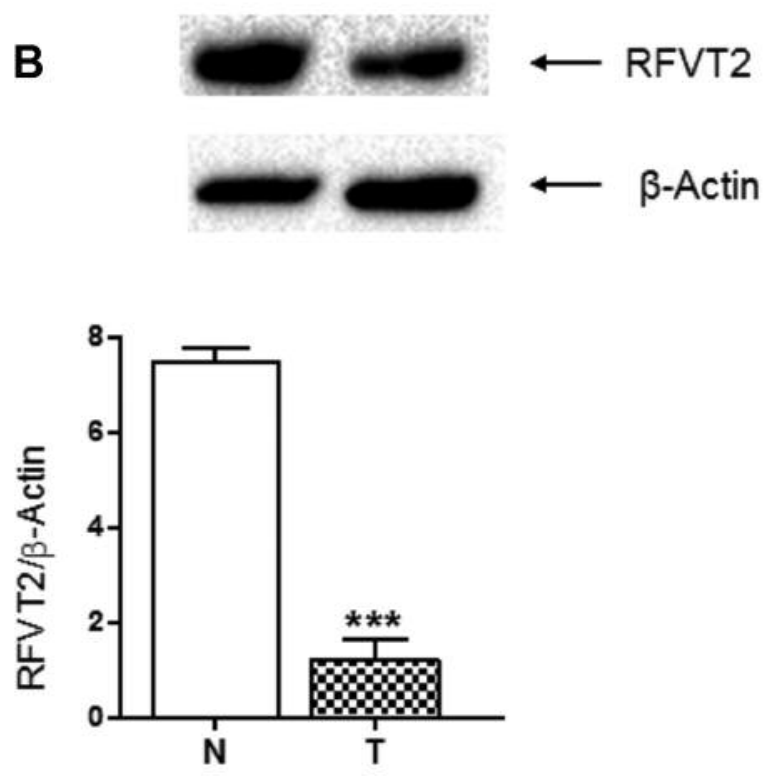

was observed between protein and gene expression of RFVT3 and $R F V T 2$ in tumor and in surrounding normal mucosa. For both of these translocators, the protein expression was reduced in tumor, whereas mRNA levels were increased, suggesting a deregulation of the transcriptional and translational response of RFVTs to tumorigenesis. The high cell turnover, or deregulation in amino acid homeostasis, which occur in tumor tissues (24) may result in a reduction in the protein levels of these transporters. These findings fit well with the apparent balance in intracellular concentration of FAD and FMN, which was found not to be significantly changed in cancer tissues. The only sign of homeostasis derangement found in the tumor tissues compared to the
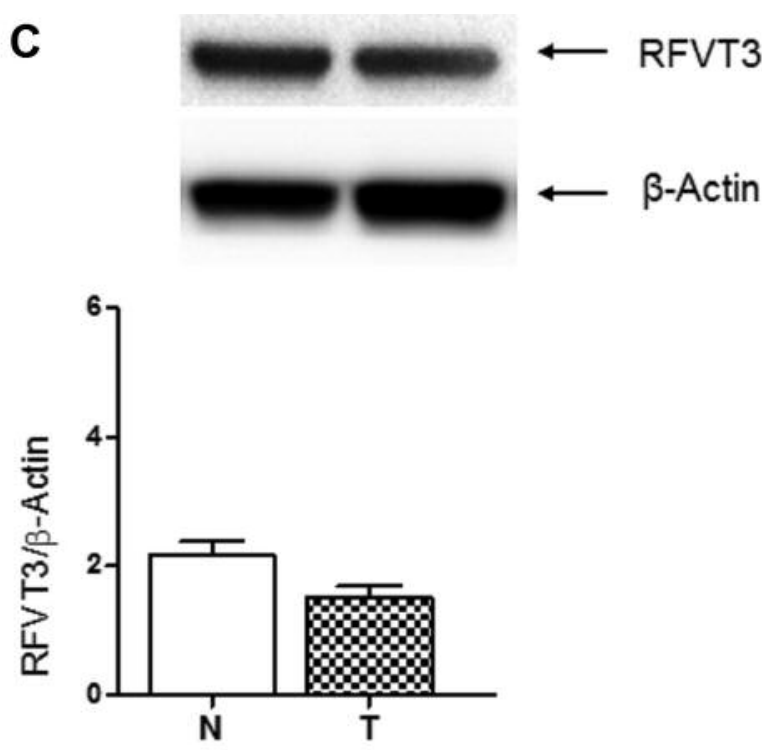

Figure 4. Western blotting analysis of the expression of riboflavin transporters (RFVT) proteins in tumor and surrounding normal mucosa. A: RFVT1, B: RFVT2, and C: RFVT3 expression normalized with that for $\beta$-actin. Significantly different at: $* * p<0.001$ and $* * * p<0.0001$, paired $t$ test. All data represent the results of three different experiments (mean $\pm S D)$.

surrounding mucosa of patients was the low intracellular level of riboflavin, probably deriving from an increased rate conversion into flavin cofactors.

In conclusion, we demonstrated that the transport of riboflavin through the intestinal barrier can be profoundly altered during cancer progression and this may explain the decrease in blood riboflavin level in patients $(19,20)$. The mechanisms involved, in both the transcriptional and posttranscriptional levels, are different for each transporter. Generally, the different behavior of the isoforms of these transporters in cell models, or, in the case of tissues, with respect to the normal mucosa, may reflect a marked alteration in the orientation/polarity of neoplastic cells (25).

Further studies are needed to understand the molecular mechanisms leading to deregulation of riboflavin transport and ascertain whether nutritional therapy with riboflavin may improve the status of patients with cancer.

\section{Acknowledgements}

The Authors thank V. Intini for her support in molecular experiments and M. A. Indiveri for linguistic consultancy. The helpful collaboration of G. Esperti, who participated as student in the early stages of this work, is also gratefully acknowledged.

This work was supported by PO Puglia FESR 2007-2013, Asse I, Linea 1.2. Accordo di Programma Quadro in materia di Ricerca Scientifica. Intervento Reti di Laboratori Pubblici di Ricerca, Progetto L.A.I.F.F.- RETE DI LABORATORI PER L'INNOVAZIONE NEL CAMPO DEGLI ALIMENTI FUNZIONALI (codice n. 47) to 
A

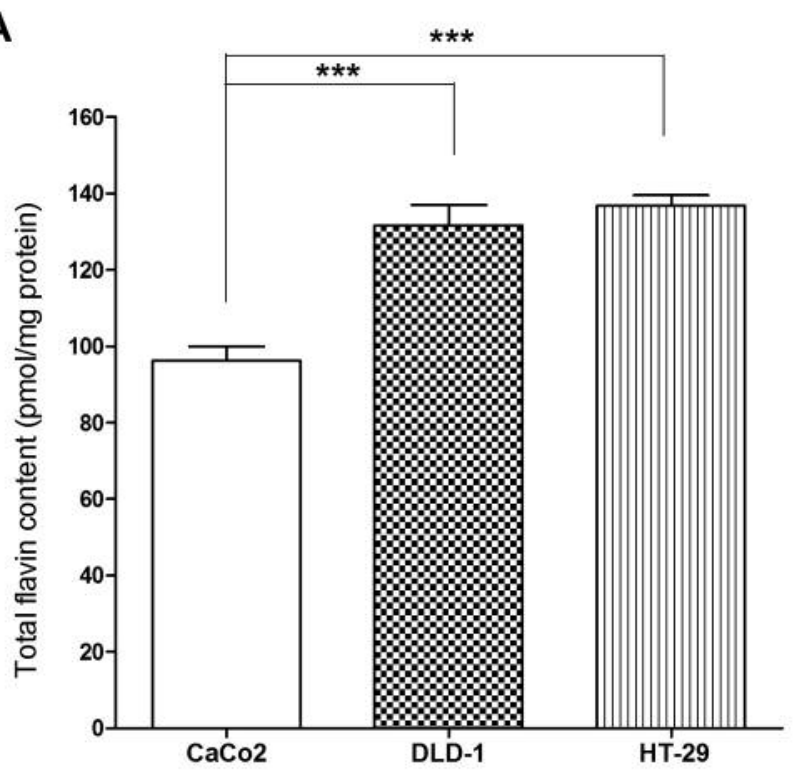

C

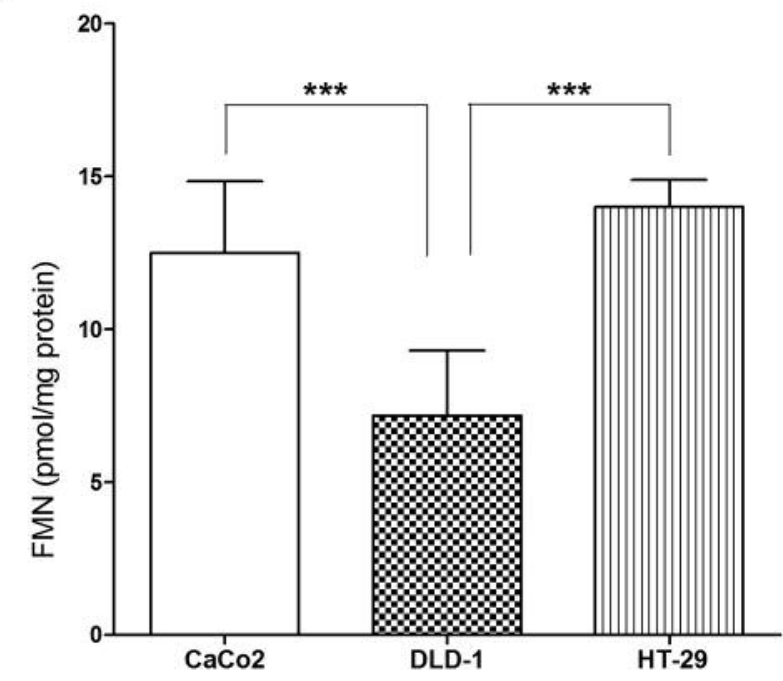

B

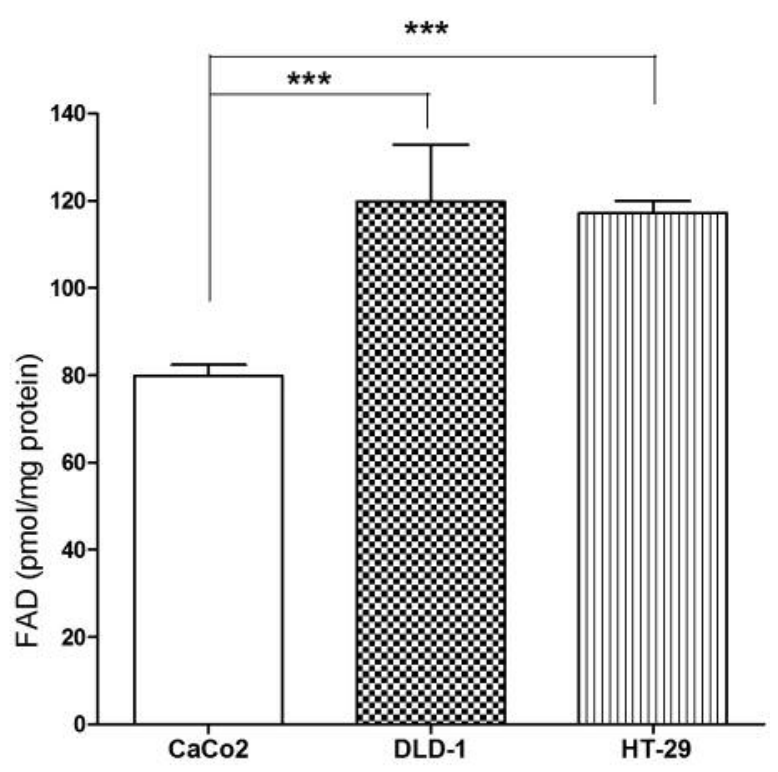

D

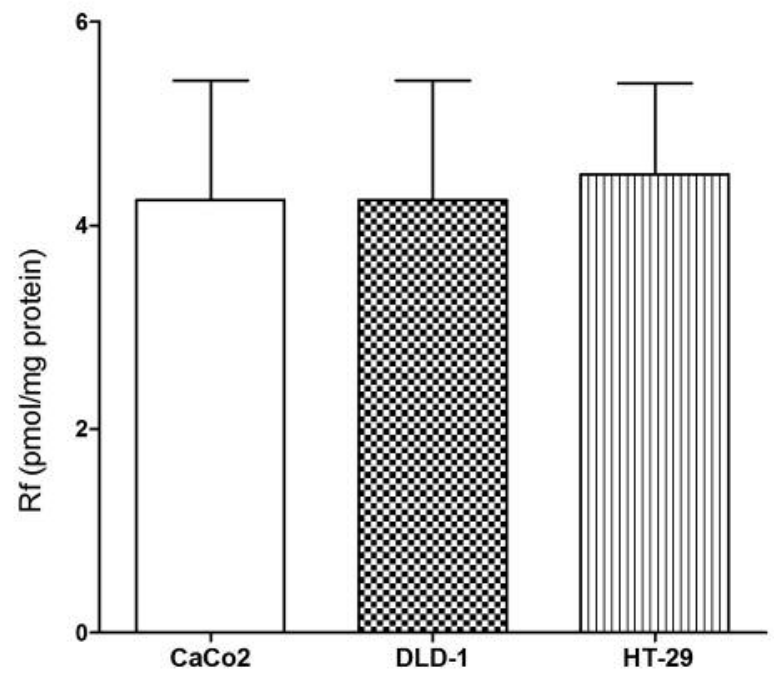

Figure 5. A: Total flavin, B: flavin adenine dinucleotide (FAD), C: flavin mononucleotide (FMN), and D: riboflavin (Rf) content in three human colon adenocarcinoma cell lines CaCo2, DLD-1 and HT-29, with different degrees of differentiation, as determined by high-performance liquid chromatography quantification measured in neutralized aliquots of perchloric acid extract (40 and $80 \mu l)$ of cell lysates ( $0.4 \mathrm{mg}$ protein). ***Significantly different at $p<0.0001$, ANOVA and Tukey's multiple comparison test. All data represent the results of three different experiments (mean $\pm S D)$.

M.G.C. and also by PON01_00937- Modelli sperimentali Biotecnologici integrati per lo sviluppo e la selezione di molecole di interesse per la salute dell'uomo MIUR (Italian Ministry of Education, University and Research) to M.B.

\section{References}

1 Barile M, Giancaspero TA, Brizio C, Panebianco C, Indiveri C, Galluccio M, Vergani L, Eberini I and Gianazza E: Biosynthesis of flavin cofactors in man: implications in health and disease. Curr Pharm Des 19: 2649-2675, 2013.
2 Barile M, Giancaspero TA, Leone P, Galluccio M and Indiveri C: Riboflavin transport and metabolism in humans. J Inherit Metab Dis 39: 545-557, 2016.

3 Massey V: The chemical and biological versatility of riboflavin. Biochem Soc Trans 28: 283-296, 2000.

$4 \mathrm{Tu}$ BP, Ho-Schleyer SC, Travers KJ and Weissman JS: Biochemical basis of oxidative protein folding in the endoplasmic reticulum. Science 290: 1571-1574, 2000.

5 Giancaspero TA, Busco G, Panebianco C, Carmone C, Miccolis A, Liuzzi GM, Colella M and Barile M: FAD synthesis and degradation in the nucleus create a local flavin cofactor pool. J Biol Chem 288: 29069-29080, 2013. 
A

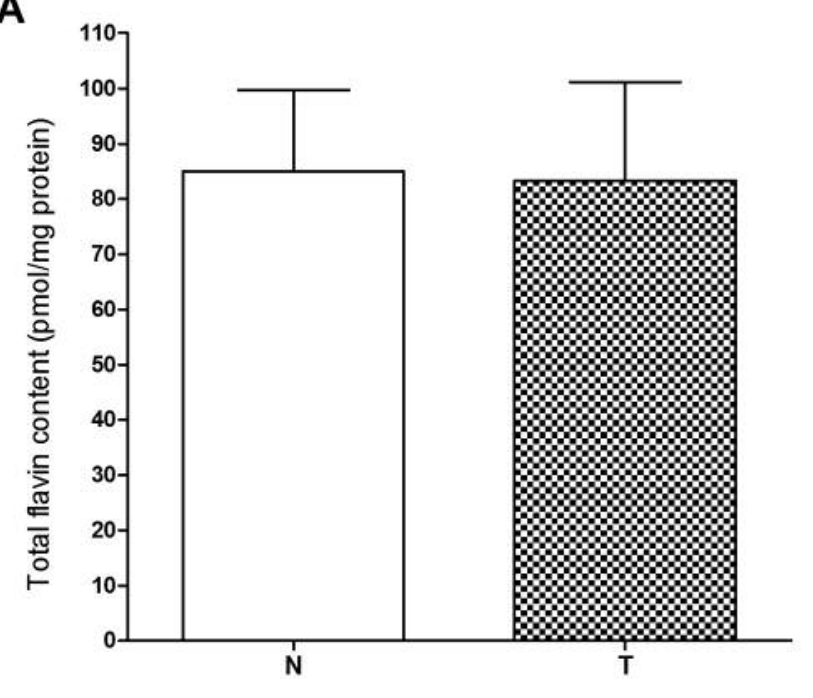

C

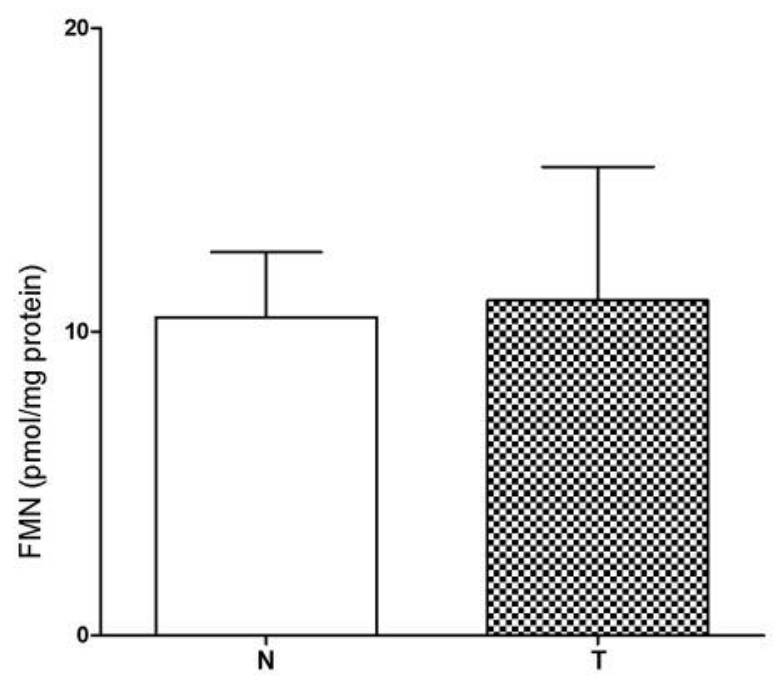

B

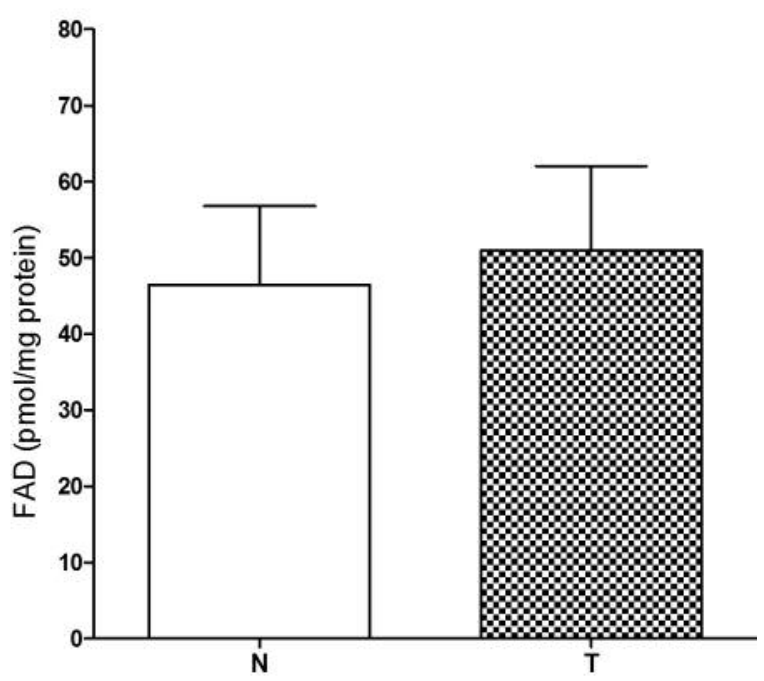

D

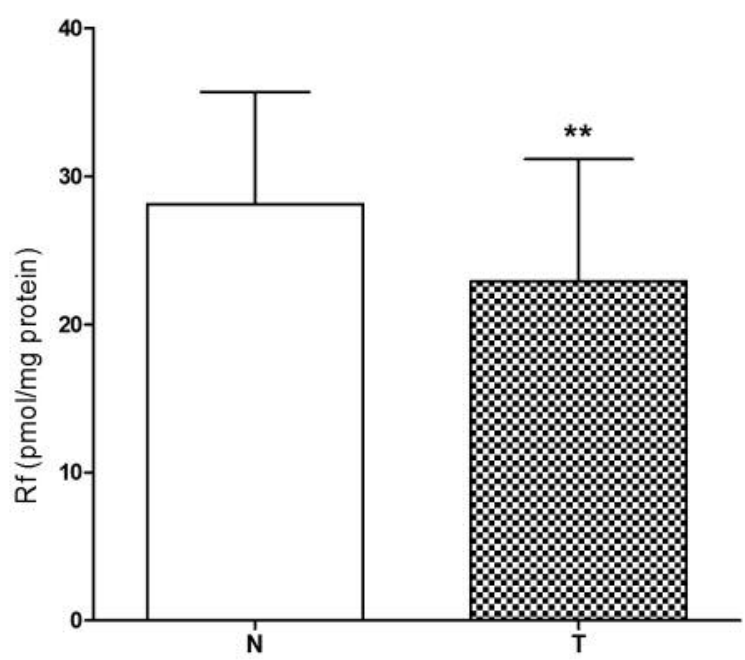

Figure 6. A: Total flavin, B: flavin adenine dinucleotide (FAD), C: flavin mononucleotide (FMN), and D: Riboflavin (Rf) content in tumor and in surrounding normal mucosa from 11 patients with colorectal cancer, as determined by high-performance liquid chromatography quantification measured in neutralized aliquots of perchloric acid extract $(40$ and $80 \mu \mathrm{l})$ of cell lysates $(0.45 \mathrm{mg}$ protein). **Significantly different at $p<0.001$, paired t-test. All data represent the results of three different experiments (mean $\pm S D$ ).

6 Yonezawa A and Inui K: Novel riboflavin transporter family RFVT/SLC52: identification, nomenclature, functional characterization and genetic diseases of RFVT/SLC52. Mol Aspects Med 34: 693-701, 2013.

7 Yonezawa A, Masuda S, Katsura T and Inui K: Identification and functional characterization of a novel human and rat riboflavin transporter, RFT1. Am J Physiol Cell Physiol 295: C632-C641, 2008.

8 Yao Y, Yonezawa A, Yoshimatsu H, Masuda S, Katsura T and Inui $\mathrm{K}$ : Identification and comparative functional characterization of a new human riboflavin transporter RFT3 expressed in the brain. $\mathrm{J}$ Nutr 140: 1220-1226, 2010.

9 Yamamoto S, Inoue K, Ohta KY, Fukatsu R, Maeda JY, Yoshida $\mathrm{Y}$ and Yuasa $\mathrm{H}$ : Identification and functional characterization of rat riboflavin transporter 2. J Biochem 145: 437-443, 2009.

10 Jaeger B and Bosch AMJ: Clinical presentation and outcome of riboflavin transporter deficiency: mini review after five years of experience. Inherit Metab Dis 39: 559-564, 2016.

11 Karthikeyan S, Zhou Q, Osterman AL and Zhang H: Ligand binding-induced conformational changes in riboflavin kinase: structural basis for the ordered mechanism. Biochemistry 42: 12532-12538, 2003.

12 Brizio C, Galluccio M, Wait R, Torchetti EM, Bafunno V, Accardi R, Gianazza E, Indiveri $\mathrm{C}$ and Barile M: Overexpression in Escherichia coli and characterization of two recombinant isoforms of human FAD synthetase. Biochem Biophys Res Commun 344: 1008-1016, 2006. 
13 Giancaspero TA, Colella M, Brizio C, Difonzo G, Fiorino GM, Leone $\mathrm{P}$, Brandsch $\mathrm{R}$, Bonomi $\mathrm{F}$, Iametti $\mathrm{S}$ and Barile $\mathrm{M}$ : Remaining challenges in cellular flavin cofactor homeostasis and flavoprotein biogenesis. Front Chem 3: 30, 2015.

14 Subramanian VS, Subramanya SB, Rapp L, Marchant JS, Ma TY and Said HM: Differential expression of human riboflavin transporters-1,-2, and-3 in polarized epithelia: a key role for RFT-2 in intestinal riboflavin uptake. Biochim Biophys Acta 1808: 3016-3021, 2011.

15 Yoshimatsu H, Yonezawa A, Yao Y, Sugano K, Nakagawa S, Omura $\mathrm{T}$ and Matsubara $\mathrm{K}$ : Functional involvement of RFVT3/SLC52A3 in intestinal riboflavin absorption. Am J Physiol Gastrointest Liver Physiol 306: G102-G110, 2014.

16 van den Donk M, Buijsse B, van den Berg SW, Ocké MC, Harryvan JL, Nagengast FM, Kok FJ and Kampman E: Dietary intake of folate and riboflavin, MTHFR C677T genotype, and colorectal adenoma risk: a Dutch case-control study. Cancer Epidemiol Biomarkers Prev 14: 1562-1566, 2005.

17 de Vogel S, Dindore V, van Engeland M, Goldbohm RA, van den Brandt PA and Weijenberg MP: Dietary folate, methionine, riboflavin, and vitamin B-6 and risk of sporadic colorectal cancer. J Nutr 138: 2372-2378, 2008.

18 Nakano E, Mushtaq S, Heath PR, Lee ES, Bury JP, Riley SA, Powers HJ and Corfe BM: Riboflavin depletion impairs cell proliferation in adult human duodenum: identification of potential effectors. Dig Dis Sci 56: 1007-1019, 2011.

19 Aili A, Hasim A, Kelimu A, Guo X, Mamtimin B, Abudula A and Upur H: Association of the plasma and tissue riboflavin levels with C20orf54 expression in cervical lesions and its relationship to HPV16 infection. PLoS One 8: e79937, 2013.

20 Eli M, Li DS, Zhang WW, Kong B, Du CS, Wumar M, Mamtimin B, Sheyhidin I and Hasim A: Decreased blood riboflavin levels are correlated with defective expression of RFT2 gene in gastric cancer. World J Gastroenterol 18: 3112-3118, 2012.
21 Tutino V, Orlando A, Russo F and Notarnicola M: Hydroxytyrosol Inhibits Cannabinoid CB1 receptor gene expression in 3T3-L1 preadipocyte cell line. J Cell Physiol 231: 483-489, 2016.

22 Olsen RK, Koňaříková E, Giancaspero TA, Mosegaard S, Boczonadi V, Mataković L, Veauville-Merllié A, Terrile C, Schwarzmayr T, Haack TB, Auranen M, Leone P, Galluccio M, Imbard A, Gutierrez-Rios P, Palmfeldt J, Graf E, Vianey-Saban C, Oppenheim M, Schiff M, Pichard S, Rigal O, Pyle A, Chinnery PF, Konstantopoulou V, Möslinger D, Feichtinger RG, Talim B, Topaloglu H, Coskun T, Gucer S, Botta A, Pegoraro E, Malena A, Vergani L, Mazzà D, Zollino M, Ghezzi D, Acquaviva C, Tyni T, Boneh A, Meitinger T, Strom TM, Gregersen N, Mayr JA, Horvath R, Barile M and Prokisch H: Riboflavin-responsive andnon-responsive mutations in FAD synthase cause multiple acylCoA dehydrogenase and combined respiratory-chain deficiency. Am J Hum Genet 98: 1130-1145, 2016.

23 Subramanian VS, Ghosal A, Kapadia R, Nabokina SM and Said HM: Molecular mechanisms mediating the adaptive regulation of intestinal riboflavin uptake process. PLoS One 10: e0131698, 2015.

24 Hayase S, Kumamoto K, Saito K, Kofunato Y, Sato Y, Okayama H, Miyamoto K, Ohki S and Takenoshita S: L-type amino acid transporter 1 expression is up-regulated and associated with cellular proliferation in colorectal cancer. Oncol Lett 14: 7410-7416, 2017.

25 Lee $\mathrm{M}$ and Vasioukhin V: Cell polarity and cancer - cell and tissue polarity as a non-canonical tumor suppressor. J Cell Sci 121: 1141-1150, 2008.
Received March 9, 2018

Revised March 29, 2018

Accepted April 2, 2018 